Research

\title{
Variation at APOE and STH loci and Alzheimer's disease Lingjun Zuo ${ }^{1,2}$, Christopher $\mathrm{H}$ van Dyck ${ }^{3}$, Xingguang Luo $^{1,2}$, Henry R Kranzler ${ }^{4}$, Bao-zhu Yang ${ }^{1,2}$ and Joel Gelernter*1,2
}

Address: ${ }^{1}$ Division of Human Genetics, Department of Psychiatry, Yale University School of Medicine, New Haven, CT, USA, ${ }^{2}$ VA Connecticut Healthcare System, West Haven Campus, CT, USA, ${ }^{3}$ Alzheimer's Disease Research Unit and Cognitive Disorders Clinic, Department of Psychiatry, Yale University School of Medicine, New Haven, CT, USA and ${ }^{4}$ Department of Psychiatry, University of Connecticut School of Medicine, Farmington, CT, USA

Email: Lingjun Zuo - Lingjun.Zuo@yale.edu; Christopher H van Dyck - christopher.vandyck@yale.edu;

Xingguang Luo - Xingguang.Luo@yale.edu; Henry R Kranzler - kranzler@psychiatry.uchc.edu; Bao-zhu Yang - Bao-zhu.yang@yale.edu;

Joel Gelernter* - Joel.Gelernter@yale.edu

* Corresponding author

Published: 07 April 2006

Behavioral and Brain Functions 2006, 2:13 doi:10.1 186/1744-908I-2-13
Received: I5 March 2006

Accepted: 07 April 2006

This article is available from: http://www.behavioralandbrainfunctions.com/content/2/I/I3

(C) 2006 Zuo et al; licensee BioMed Central Ltd.

This is an Open Access article distributed under the terms of the Creative Commons Attribution License (http://creativecommons.org/licenses/by/2.0), which permits unrestricted use, distribution, and reproduction in any medium, provided the original work is properly cited.

\begin{abstract}
Background: The apolipoprotein E (APOE) and tau proteins play important roles in the pathological development of Alzheimer's disease (AD). Many studies have shown an association between the APOE gene and AD. Association between AD and the newly discovered saitohin (STH) gene, nested within the intron of the tau gene, has been reported. The present study aimed to elucidate the association between APOE and AD, and between STH and AD in our sample.
\end{abstract}

Methods: The functional polymorphisms, rs429358 and rs74I2, in the APOE gene (which together define the $\varepsilon 2, \varepsilon 3$, and $\varepsilon 4$ alleles), and the Q7R SNP in the STH gene, were genotyped in 369 patients with $A D$ and 289 healthy European-Americans. The associations between these two genes and AD were analyzed in a case-control design.

Results: Consistent with previously reported results, the frequencies of the APOE $\varepsilon 4$ allele, $\varepsilon 4 / \varepsilon 4$ genotype and $\varepsilon 3 / \varepsilon 4$ genotype were significantly higher in $A D$ cases than controls; the $\varepsilon 4 / \varepsilon 4$ genotype frequency was significantly higher in early-onset $A D$ (EOAD) than late-onset $A D$ (LOAD); the frequencies of the $\varepsilon 2$ allele, $\varepsilon 3$ allele, $\varepsilon 3 / \varepsilon 3$ genotype and $\varepsilon 2 / \varepsilon 3$ genotype were significantly lower in AD cases than controls. Positive likelihood ratios (LRs ${ }^{+}$) of APOE alleles and genotypes increased in a linear trend with the number of $\varepsilon 4$ alleles and decreased in a linear trend with the number of $\varepsilon 2$ or $\varepsilon 3$ alleles. There was no significant difference in the STH allele and genotype frequency distributions between $A D$ cases and controls.

Conclusion: This study confirmed that the $\varepsilon 4$ allele is a dose-response risk factor for AD and the $\varepsilon 4 / \varepsilon 4$ genotype was associated with a significantly earlier age of onset. Moreover, we found that the $\varepsilon 2$ allele was a dose-response protective factor for AD and the $\varepsilon 3$ allele exerted a weaker doseresponse protective effect for risk of $A D$ compared with $\varepsilon 2$. In a clinical setting, APOE genotyping could offer additional biological evidence of whether a subject may develop AD, but it is not robust enough to serve as an independent screening or predictive test in the diagnosis of AD. STH variation was not significantly associated with $A D$ in our sample. 


\section{Background}

Alzheimer's disease (AD) is the most common cause of dementia. It is a primary neurodegenerative cerebral disease in the elderly, characterized by two major histopathologic changes in the brain, i.e., extracellular amyloid plaques and intracellular neurofibrillary tangles $[1,2]$.

Apolipoprotein E (APOE) is one of the major cholesterol transport proteins. It exists in three major isoforms, APOE2, APOE3 and APOE4. The three APOE isoforms differ in the $112^{\text {th }}$ and $158^{\text {th }}$ residues of their primary structures (Figure 1); these differences are classified as SNPs rs429358 and rs7412, respectively. The APOE3 protein has higher receptor affinity than the variant types APOE2 and APOE4. Substitution of the basic amino acid Arg158 in APOE3 by the neutral amino acid Cys158 in APOE2 results in the receptor affinity of APOE2 being reduced to $2 \%$ of that of APOE3 [3]. In the central nervous system, APOE mediates the uptake and redistribution of cholesterol, and different APOE isoforms modify cholesterol homeostasis by preferentially associating with specific lipoprotein particles [4]. The role of APOE in modifying cholesterol homeostasis in the brain may contribute to the relationship between APOE and AD. Furthermore, APOE exists inside the amyloid plaque, where it can bind to $\beta$-amyloid $(\mathrm{A} \beta)$, which is a major component of the plaque [5]. Studies have shown that APOE interacts with $\mathrm{A} \beta$ to form a stable complex, altering the deposition of $\mathrm{A} \beta$ and affecting $\mathrm{A} \beta$-induced neurotoxicity [6].
Moreover, APOE may be involved in Alzheimer's disease through a tau pathway. Studies have indicated that tau plays an important role in the physiopathology of Alzheimer's disease and that an extended haplotype (H1), covering the entire tau gene, including a 238 bp insertion in intron 9, is associated with AD [2,7-12], although these observations have not always been confirmed by other studies. APOE2 and APOE3 can bind to tau and prevent tau from being hyperphosphorylated. Although APOE4 also binds to tau, it cannot prevent tau from hyperphosphorylation, but destabilizes tau. The hyperphosphorylated tau can decrease tau's affinity for microtubules and severely disrupt microtubule stability, which has been postulated to be an important step in the formation of the paired helical filament (PHF) involved in neuronal degeneration. This may be part of the mechanism of APOE's important role in the etiology of $\mathrm{AD}$.

APOE2, APOE3 and APOE4 are encoded by the $\varepsilon 2, \varepsilon 3$ and $\varepsilon 4$ alleles, respectively [13]. The roles of these alleles in modulating risk for AD have been widely studied. (a) The $\varepsilon 4$ allele contributes to the risk for AD across most populations [e.g., [14,15]]. (b) $\mathrm{AD}$ patients with the $\varepsilon 4$ allele have an earlier age-of-onset than those without the $\varepsilon 4$ allele [e.g., [16,17]]. (c) The $\varepsilon 4$ allele has a significant dose effect on the risk for AD [e.g., [18-20]]. (d) The $\varepsilon 2$ allele may protect individuals from being affected with $\mathrm{AD}$ [e.g., $[14,15]]$.

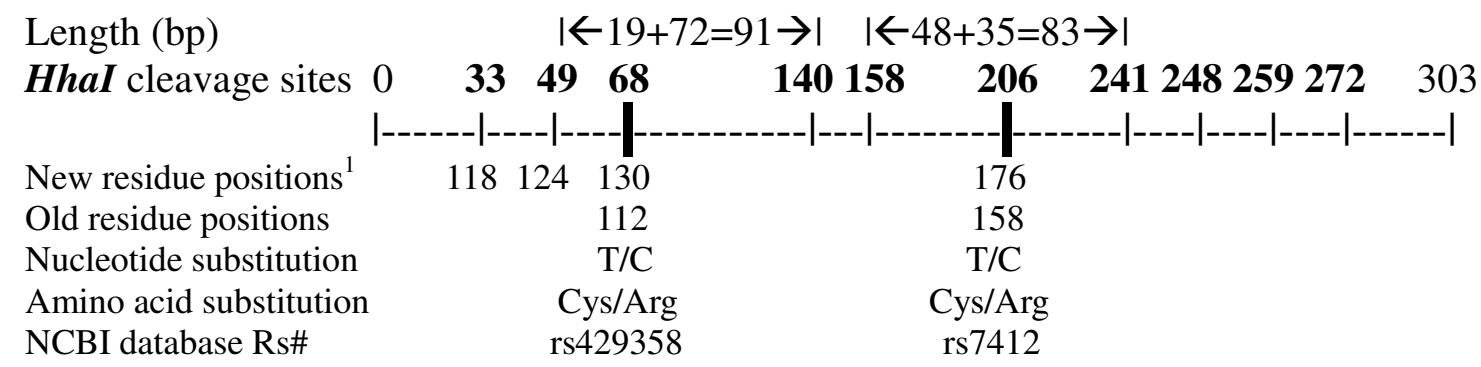

\section{Figure I}

Hhal cleavage sites within the APOE amplicon. I The residue positions are updated in the NCBI SNP database http://

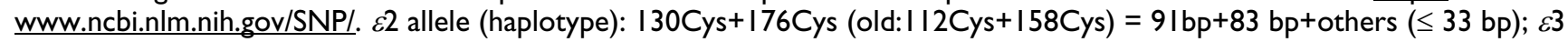
allele (haplotype): I 30Cys+ I 76Arg (old: I I 2Cys+ I 58Arg) = 9I bp +48 bp +35 bp+others ( $\leq 33$ bp); $\varepsilon 4$ allele (haplotype): I 30Arg+ | 76Arg (old: I I 2Arg+ I 58Arg) = 72+48+35+ |9+others ( $\leq 33 \mathrm{bp})$. 
Saitohin (STH), an intronless gene, has been shown to be nested in the intron between exons 9 and 10 of the tau gene, $2.5 \mathrm{~kb}$ downstream from exon 9. This region is functionally critical due to the splicing of exon 10 . The special location of the STH gene has prompted investigation into its possible role in $\mathrm{AD}$ and other neurodegenerative disorders. The A224G polymorphism in the STH gene, which causes a glutamine $(\mathrm{Q})$ to arginine $(\mathrm{R})$ substitution at residue $7(\mathrm{Q} 7 \mathrm{R})$, is in linkage disequilibrium with the extended tau H1/H2 haplotype [21,22]. That is, the $S T H$ $\mathrm{Q}$ allele is associated with tau haplotype $\mathrm{H} 1$, and the $S T H$ $\mathrm{R}$ allele is associated with haplotype $\mathrm{H} 2$. An initial study by Conrad et al. [23] demonstrated that the Q7R polymorphism in the $S T H$ gene was associated with risk for $\mathrm{AD}$. The STH gene has also been associated with autosomal dominant frontotemporal dementia (FTD), progressive supranuclear palsy (PSP) and Pick's disease [21,23-25]. Nevertheless, these findings remain controversial [22,25-29].

The purpose of the present study was to elucidate the associations between the variants at APOE and STH loci and $\mathrm{AD}$ in our samples, and to explore the gene-dose effects and evaluate the implications of variation at the APOE gene in the diagnosis of $\mathrm{AD}$.

\section{Methods and materials Subjects}

The sample included 658 European-Americans, including 369 patients with $\mathrm{AD}$ and 289 healthy controls. The diagnosis of $\mathrm{AD}$ was based on criteria of the National Institute of Neurological and Communicative Disorders and Stroke and Alzheimer's disease and Related Disorders Association (NINCDS-ADRDA) [30]. The AD cases were divided into an early-onset (EOAD) group and a lateonset (LOAD) group based on an age-of-onset of 70 years $[27,29]$. Each subject was evaluated for an approximate date of $\mathrm{AD}$ onset, based on careful review of medical records and detailed interviews with one or more primary caregivers. The date of onset was operationally defined as the date at which the "earliest definite AD symptom" appeared. The mean age of $\mathrm{AD}$ patients was $73.6 \pm 8.4$ years (range: 51.8 to 92.7 ); the mean age-of-onset was $69.3 \pm 8.3$ years (range: 44.6 to $86.7 ; 3$ subjects unknown); 143 were male, 226 were female; 180 had positive family history $\left(\mathrm{FH}^{+}\right), 184$ had negative family history $\left(\mathrm{FH}^{-}\right)$, and 5 had unknown family history. Family history of AD was assessed using the Alzheimer Dementia Risk Questionnaire (ADRQ) [31] and the Dementia Questionnaire (DQ) [32]. Family history was considered positive if at least one first-degree relative met criteria for primary degenerative dementia. No cases suggestive of autosomal dominant transmission were identified.
There were two sets of control subjects who were differentiated based on the method of ascertainment. The first set of healthy controls $(n=185)$ was recruited through advertisements in the community. They were screened using the Structured Clinical Interview for DSM-III-R (SCID), the Computerized Diagnostic Interview Schedule for DSMIII-R (C-DIS-R), the Schedule for Affective Disorders and Schizophrenia (SADS) [33], or an unstructured interview, to exclude major Axis I disorders, including substance dependence, psychotic disorders, mood disorders, anxiety

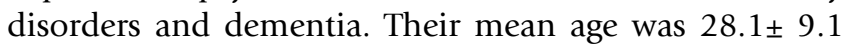
years (range: 18.0 to 52.0 ); 81 were male and 104 were female. The second set of healthy controls $(n=104)$ was recruited primarily from among spouses of $\mathrm{AD}$ patients. Their mean age was $63.3 \pm 16.3$ years (range: 21.1 to 87.5 ); 49 were male and 55 were female. They were evaluated as being in generally good medical health for their age on the basis of a comprehensive evaluation that included medical history, physical and neurological examinations, serum chemistries, thyroid function studies, complete blood count, B12, folate, VDRL, urinalysis, electrocardiogram, and brain MRI or CT. The second set of controls was also required to have no significant evidence of cognitive impairment, as indicated by a Mini-Mental State Examination (MMSE) [34] score $>27$. Subjects were recruited at Yale University School of Medicine, the University of Connecticut Health Center, or the VA Connecticut Healthcare System, West Haven Campus. Informed consent was obtained from all the patients and the controls. This study was performed after approval by the appropriate Institutional Review Boards (IRBs).

\section{Genotyping}

Genomic DNA was extracted from peripheral blood by standard methods. The region flanking the two target markers within exon 5 of APOE, rs429358 and rs7412, was amplified by a single polymerase chain reaction (PCR) using the following primers [35]: APOE-A: 5'CGGGCACGGCTGTCCAAGGAG-3' and APOE-C: 5'CACGCGGCCCTGTTCCACgAG-3' (g is mismatched). PCR was performed in a final volume of $10 \mu \mathrm{l}$ with $1 \times$ PC2 buffer (Ab Peptides, Inc., St. Louis, MO), $1 \mathrm{M}$ betaine, 0.5 units of KlenTaq polymerase (Ab Peptides, Inc., St. Louis, $\mathrm{MO}$ ) and $10 \mathrm{ng}$ DNA. PCR conditions were set as follows: $95^{\circ} \mathrm{C}$ for $5 \mathrm{~min}$; 35 cycles of $95^{\circ} \mathrm{C}$ for $30 \mathrm{~s}, 64^{\circ} \mathrm{C}$ for $30 \mathrm{~s}$, and $72^{\circ} \mathrm{C}$ for $30 \mathrm{~s}$. The genotypes were analyzed on $5 \%$ metaphor agarose gel after digestion with HhaI (New England Biolabs Inc., Beverly, MA). The size of the PCR product was $303 \mathrm{bp}$, within which there are eight constant HhaI cleavage sites (GCG|C) and two variant HhaI cleavage sites (see Figure 1).

The region flanking the Q7R marker in the STH gene was amplified by PCR using the primers from the initial study by Conrad et al. [23]. PCR was performed in a final vol- 
ume of $15 \mu$ with $1 \times$ PC2 buffer, $1 \mathrm{M}$ betaine, 0.75 units of KlenTaq polymerase and $25 \mathrm{ng}$ DNA. PCR conditions were set as follows: $95^{\circ} \mathrm{C}$ for $5 \mathrm{~min} ; 30$ cycles of $95^{\circ} \mathrm{C}$ for $30 \mathrm{~s}, 60^{\circ} \mathrm{C}$ for $30 \mathrm{~s}$, and $72^{\circ} \mathrm{C}$ for $30 \mathrm{~s}$. The genotypes were analyzed on $3 \%$ metaphor agarose gel after digestion with HinfI (New England Biolabs Inc., Beverly, MA). The size of the PCR product was $226 \mathrm{bp}$. The R allele (Arginine, CGA) can be cut by HinfI (97 bp+74 bp+55 bp), whereas the Q allele (Glutamine, CAA) cannot (171 bp+55 bp).

\section{Statistical analysis}

The comparisons in allele and genotype frequency distributions between two groups were performed with Fisher's exact test. Bonferroni correction was used to adjust the $\alpha$ level of multiple comparisons [36].

Positive predictive values (PPVs) were calculated with Bayes' rule [37]. $P(A D)$ was the prior probability of developing $\mathrm{AD}$, i.e., the prevalence of $\mathrm{AD}$ (see Formula). We used $15 \%$ as the estimated prevalence of $\mathrm{AD}$ [38]; P(Controls $) \approx 1-P(A D) ; P(\varepsilon \mid A D)$ was allele or genotype frequency in $\mathrm{AD}$ cases, and $P(\varepsilon \mid$ Controls $)$ was allele or genotype frequency in controls. Both $P(\varepsilon \mid A D)$ and $P(\varepsilon \mid$ Controls $)$ were estimated from the present study; $\hat{P}(A D \mid \varepsilon)$ was the posterior probability of developing $\mathrm{AD}$ given a certain allele or genotype.

$$
\hat{P}(A D \mid \varepsilon)=\frac{P(\varepsilon \mid A D) \cdot P(A D)}{P(\varepsilon \mid A D) \cdot P(A D)+P(\varepsilon \mid \text { Controls }) \cdot P(\text { Controls })}
$$

Positive likelihood ratios $\left(\mathrm{LRs}^{+}\right)$were calculated by dividing the allele or genotype frequencies in $\mathrm{AD}$ cases by those in controls [39]. For example, if the frequency of the $\varepsilon 4 / \varepsilon 4$ genotype is 0.139 in $\mathrm{AD}$ cases and 0.037 in controls, then the $\mathrm{LR}^{+}$is equal to $0.139 / 0.037=3.757$.

The dose effect of the APOE gene, i.e., the relationship between the risk for $\mathrm{AD}$ and the number of $A P O E$ alleles, was tested by the chi-square test for trend using the software EPISTAT [40]. The relationships between the number of APOE alleles and their $\mathrm{LRs}^{+}$were tested with Spearman's rank correlation analysis implemented in SPSS 13.0 (SPSS Inc., Chicago, IL). Gene dose effects for $A P O E$ were plotted using a polynomial curve-fitting plot method in S-PLUS 2000 (Mathsoft Engineering \& Education, Inc., Cambridge, MA).

Age, sex, and AD family history are confounders that may cause false positive or false negative results. Thus, we used stepwise logistic regression analysis to investigate the association between the risk for $\mathrm{AD}$ and the number of $A P O E$ and STH alleles, controlling for the effects of the potential confounders. In the stepwise logistic regression model, the diagnosis served as the dependent variable; the independent variables included the number of APOE $\varepsilon 4$ alleles, the number of $A P O E \varepsilon 2$ alleles, the number of $S T H$ $\mathrm{R}$ alleles, the interaction between $S T H \mathrm{R}$ allele and APOE alleles, age, sex and AD family history. This analysis was performed with SPSS 13.0 software.

\section{Results}

There was no significant difference in allele frequency distributions, genotype frequency distributions or dose effects of APOE and STH gene between our two sets of controls, so we combined the two control groups into one larger control group.

\section{Associations of APOE alleles and genotypes with Alzheimer's disease}

The comparisons of allele and genotype frequency distributions between AD cases and controls are shown in Tables 1 and 2. The genotype frequency distributions in both $\mathrm{AD}$ cases and controls were in Hardy-Weinberg equilibrium (HWE).

The overall allele and genotype frequency distributions in $\mathrm{AD}$ cases were significantly different from those in controls. The frequencies of the $\varepsilon 4$ allele, $\varepsilon 3 / \varepsilon 4$ and $\varepsilon 4 / \varepsilon 4$ genotypes were significantly higher in $\mathrm{AD}$ cases than in controls and the frequencies of the $\varepsilon 2, \varepsilon 3$ alleles, $\varepsilon 2 / \varepsilon 3$ and $\varepsilon 3 / \varepsilon 3$ genotypes were significantly lower in $\mathrm{AD}$ cases than in controls.

We also compared allele and genotype frequencies in $\mathrm{AD}$ subgroups (EOAD, LOAD, $\mathrm{FH}^{+} \mathrm{AD}, \mathrm{FH}^{-} \mathrm{AD}$, male $\mathrm{AD}$ and female $\mathrm{AD}$ ) with those in controls. The overall allele and genotype frequency distribution in each of the AD subgroups was significantly different from that in controls. Specifically, the frequencies of the $\varepsilon 4$ allele and the $\varepsilon 3 / \varepsilon 4$ genotype in each of the $\mathrm{AD}$ subgroups, and the $\varepsilon 4 / \varepsilon 4$ genotype in $\mathrm{EOAD}, \mathrm{FH}^{+} \mathrm{AD}, \mathrm{FH}^{-} \mathrm{AD}$, and female $\mathrm{AD}$ were significantly higher than those in controls; the frequencies of the $\varepsilon 3$ allele and the $\varepsilon 3 / \varepsilon 3$ genotype in each of the AD subgroups, and the $\varepsilon 2$ allele in $\mathrm{EOAD}, \mathrm{FH}^{+} \mathrm{AD}$ and female $\mathrm{AD}$ were significantly lower than those in controls. The genotype frequency distributions were significantly different between EOAD and LOAD [(the $\varepsilon 4 / \varepsilon 4$ genotype frequency in $\operatorname{EOAD}(0.203)$ was significantly higher than that in LOAD (=0.082)]. Among these differences, the nominal difference in the frequency of the $\varepsilon 2$ allele between cases and controls was not statistically significant after Bonferroni correction.

Stepwise logistic regression analyses showed that after adjusting for age, sex, and $\mathrm{AD}$ family history, the $\varepsilon 4$ and $\varepsilon 2$ alleles were still significantly associated with risk for $\mathrm{AD}\left(P_{\varepsilon 4}=0.014\right.$, adjusted $\mathrm{OR}_{\varepsilon 4}=1.86,95 \% \mathrm{Cl}_{\varepsilon 4}: 1.13-$ 
Table I: Distributions of allele frequencies of APOE and STH gene variations in European-American subjects

\begin{tabular}{|c|c|c|c|c|c|c|c|c|c|c|c|c|c|c|c|c|c|c|}
\hline & \multicolumn{7}{|c|}{ APOE alleles } & \multicolumn{4}{|c|}{ Exact $p$-values } & \multicolumn{5}{|c|}{ STH alleles } & \multirow[t]{3}{*}{ Exact $p$-values } & \\
\hline & \multicolumn{2}{|c|}{$\varepsilon 2$} & \multicolumn{2}{|c|}{$\varepsilon 3$} & \multicolumn{2}{|c|}{$\varepsilon 4$} & \multirow{2}{*}{$\begin{array}{l}\text { Total } \\
2 \mathrm{~N}\end{array}$} & \multirow[t]{2}{*}{$\varepsilon 2$} & \multirow[t]{2}{*}{$\varepsilon 3$} & \multirow[t]{2}{*}{$\varepsilon 4$} & \multirow[t]{2}{*}{ Total } & \multicolumn{2}{|c|}{ Q } & \multicolumn{2}{|c|}{$\mathrm{R}$} & \multirow{2}{*}{$\begin{array}{l}\text { Total } \\
2 \mathrm{~N}\end{array}$} & & \\
\hline & $f$ & $\mathrm{n}$ & $f$ & $\mathrm{n}$ & $f$ & $\mathrm{n}$ & & & & & & $f$ & $\mathrm{n}$ & $f$ & $\mathrm{n}$ & & & \\
\hline AD & 0.024 & 17 & 0.617 & 443 & 0.359 & 258 & 718 & 0.001 & $6.0 * 10^{-12}$ & $2.4 * 10^{-18}$ & $1.2 * 10-18$ & 0.767 & 439 & 0.233 & 133 & 572 & 0.345 & I \\
\hline EOAD & 0.017 & 6 & 0.590 & 203 & 0.392 & 135 & 344 & 0.002 & $4.7 * 10-11$ & $6.8 * 10-17$ & $2.5 * 10^{-17}$ & 0.771 & 216 & 0.229 & 64 & 280 & 0.506 & 2 \\
\hline LOAD & 0.027 & 10 & 0.644 & 237 & 0.329 & $12 \mid$ & 368 & 0.022 & $3.6 * 10^{-7}$ & $3.1 * 10-11$ & $5.5 * 10-11$ & 0.762 & 218 & 0.238 & 68 & 286 & 0.348 & 2 \\
\hline $\mathrm{FH}^{+}$ & 0.014 & 5 & 0.590 & 204 & 0.396 & 137 & 346 & $6.8 * 10^{-4}$ & $4.9 * 10-11$ & $2.1 * 10-16$ & $2.3 * 10^{-17}$ & 0.737 & 205 & 0.263 & 73 & 278 & 0.094 & 2 \\
\hline $\mathrm{FH}^{-}$ & 0.030 & 11 & 0.641 & 232 & 0.329 & 119 & 362 & 0.051 & $2.2 * 10^{-7}$ & $4.1 * \mid 0^{-11}$ & $1.1 * 10-10$ & 0.796 & 226 & 0.204 & 58 & 284 & 1.000 & 2 \\
\hline Male & 0.032 & 9 & 0.635 & 179 & 0.333 & 94 & 282 & 0.093 & $3.9 * 10^{-5}$ & $1.7 * 10^{-7}$ & $3.9 * 10^{-7}$ & 0.738 & 155 & 0.262 & 55 & 210 & 0.145 & 3 \\
\hline Female & 0.018 & 8 & 0.606 & 264 & 0.376 & 164 & 436 & 0.008 & $7.0 * 10^{-8}$ & $9.8 * 10^{-12}$ & $4.9 * 10^{-12}$ & 0.785 & 284 & 0.215 & 78 & 362 & 1.000 & 3 \\
\hline Controls & 0.061 & 30 & 0.801 & 394 & 0.138 & 68 & 492 & & & & & 0.794 & 313 & 0.206 & 81 & 394 & & \\
\hline Male & 0.065 & 15 & 0.800 & 184 & 0.135 & 31 & 230 & & & & & 0.805 & 140 & 0.195 & 34 & 174 & & \\
\hline Female & 0.057 & 15 & 0.802 & 210 & 0.141 & 37 & 262 & & & & & 0.786 & 173 & 0.214 & 47 & 220 & & \\
\hline
\end{tabular}

f, frequency; $n$, number of alleles; $N$, number of individuals; $2 \mathrm{~N}$, number of chromosomes; $A D$, Alzheimer's disease; EOAD, early-onset $A D$ ( $\triangle 70 y r s) ; L O A D$, late-onset $A D$ (>70yrs); Controls, the total controls combining two subgroups through two different diagnostic evaluations. The numbers in last column denote: I. Comparing overall AD with controls ( $\alpha$ was set at 0.017 for each APOE allele comparison); 2 .

Comparing EOAD, LOAD, FH+AD and FH-AD with controls respectively ( $\alpha$ was set at 0.003 for each APOE allele comparison); 3. Comparing male $A D$ with male controls and female $A D$ with female controls ( $\alpha$ was set at 0.003 for each APOE allele comparison).

Table 2: Distributions of the genotype frequencies of the APOE gene variations in European-American subjects

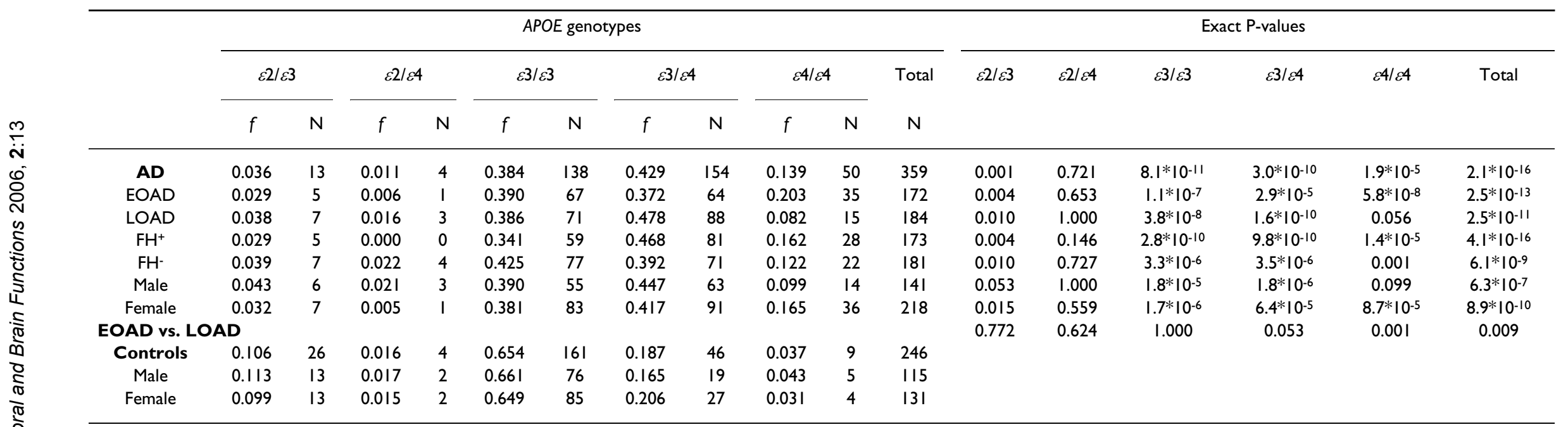

f, N, AD, EOAD, LOAD, Controls and the comparing methods see Table I. EOAD vs. LOAD, comparing EOAD and LOAD. $\alpha$ was set at 0.010 (or 0.002 ) for each genotype comparison between overall AD and controls (or between $A D$ subgroups and controls), referring to Table $I$. $\varepsilon 2 / \varepsilon 3$, the genotype consists of allele $\varepsilon 2$ and allele $\varepsilon 3$; as analogy. 
Table 3: Interpretation of PPVs and LRs ${ }^{+}$of APOE alleles and genotypes

\begin{tabular}{|c|c|c|c|c|}
\hline allele/genotype & $\operatorname{PPV}[\hat{P}(A D \mid \varepsilon)]$ & $\mathrm{LR}^{+}$ & LR range ${ }^{l}$ & Significance for diagnosis \\
\hline & & & $>10$ & greatly increasing risk for AD \\
\hline & & & $5 \sim 10$ & moderately increasing risk for $A D$ \\
\hline$\varepsilon 4 / \varepsilon 4$ & $39.90 \%$ & 3.76 & $2 \sim 5$ & small increase in risk for $A D$ \\
\hline$\varepsilon 4$ & $31.50 \%$ & 2.60 & & \\
\hline \multirow[t]{3}{*}{$\varepsilon 3 / \varepsilon 4$} & $28.80 \%$ & 2.29 & & \\
\hline & & & $1 \sim 2$ & minimally increasing risk for $A D$ \\
\hline & I5.00\% (population prevalence) & & I & no change in risk for $A D$ \\
\hline$\varepsilon 3$ & $12.00 \%$ & 0.77 & $0.5 \sim 1$ & minimally decreasing risk for $A D$ \\
\hline$\varepsilon 2 / \varepsilon 4$ & $10.82 \%$ & 0.69 & & \\
\hline$\varepsilon 3 / \varepsilon 3$ & $9.40 \%$ & 0.59 & & \\
\hline$\varepsilon 2$ & $6.50 \%$ & 0.39 & $0.2 \sim 0.5$ & small decrease in risk for $A D$ \\
\hline \multirow[t]{3}{*}{$\varepsilon 2 / \varepsilon 3$} & $5.70 \%$ & 0.34 & & \\
\hline & & & $0.1 \sim 0.2$ & moderately decreasing risk for $A D$ \\
\hline & & & $<0.1$ & greatly decreasing risk for $A D$ \\
\hline
\end{tabular}

PPV, estimated positive predictive value; $L R^{+}$, positive likelihood ratios.

IReference to [39].

$3.05 ; P_{\varepsilon 2}=0.041$, adjusted $\mathrm{OR}_{\varepsilon 2}=0.36,95 \% \mathrm{Cl}_{\varepsilon 2}: 0.13-$ $0.96)$.

PPVs and LRs+ of the APOE gene for the diagnosis of AD PPVs and $\mathrm{LRs}^{+}$of APOE alleles and genotypes for AD are listed in Table 3. Both PPVs and $\mathrm{LRs}^{+}$of APOE alleles and genotypes were in the following order: $\varepsilon 4 / \varepsilon 4>\varepsilon 4>\varepsilon 3 / \varepsilon 4$ $>\varepsilon 3>\varepsilon 2 / \varepsilon 4>\varepsilon 3 / \varepsilon 3>\varepsilon 2>\varepsilon 2 / \varepsilon 3$.

We also compared PPVs for different subtypes of AD. PPVs of the $\varepsilon 4 / \varepsilon 4$ genotype were much higher in $\operatorname{EOAD}(49.2 \%$ vs. $28.1 \%$ for $\mathrm{LOAD})$, female $\mathrm{AD}(48.4 \%$ vs. $28.9 \%$ for male $\mathrm{AD}$ ) and $\mathrm{FH}^{+} \mathrm{AD}$ (43.6\% vs. $36.8 \%$ for $\left.\mathrm{FH}^{-} \mathrm{AD}\right)$. In addition, the PPV for the $\varepsilon 3 / \varepsilon 4$ genotype was higher in LOAD (31.1\%) than EOAD (26.0\%). Finally, the PPVs were lower for $\mathrm{FH}^{+} \mathrm{AD}$ for the $\varepsilon 2$ allele and the $\varepsilon 2 / \varepsilon 3$ genotype $\left(3.9 \%, 4.6 \%\right.$, respectively) than for $\mathrm{FH}^{-} \mathrm{AD}(8.0 \%$, $6.1 \%$, respectively).

\section{Gene dose effects of the APOE gene on the risk for AD (Table 4 and Figure 2)}

The chi-square test for trend analyses showed that there was a significant positive correlation between the number of $\varepsilon 4$ alleles and risk for $\mathrm{AD}$ and a significant negative correlation between the number of $\varepsilon 2$ or $\varepsilon 3$ alleles and risk for AD.

Similarly, the Spearman's rank correlation analysis showed that the number of APOE alleles was significantly correlated with $\mathrm{LR}^{+}$, which increased linearly with the number of the $\varepsilon 4$ alleles (correlation coefficient $\mathrm{r}_{\varepsilon 4}=1.0$; slope $\mathrm{K}_{\varepsilon 4}=1.602$ ) and decreased linearly with the number of $\varepsilon 2$ or $\varepsilon 3$ alleles (correlation coefficient $\mathrm{r}_{\varepsilon 2 \text { or } \varepsilon 3}=$ 1.0; slope $\mathrm{K}_{\varepsilon 2}=-0.543$; slope $\mathrm{K}_{\varepsilon 3}=-1.122$ ).

\section{Association of the STH gene with AD}

No significant difference in STH allele and genotype frequency distributions was found between AD cases and controls. Even after adjusting for potential confounding by the APOE gene, age, sex and AD family history, stepwise logistic analyses showed no association of STH alleles or genotypes with AD.

\section{Interactive effects between the STH gene and the APOE gene}

Using STH genotypes, we grouped all subjects into QQ, $\mathrm{RR}$ and $\mathrm{QR}$ groups. We then compared $A P O E$ allele and genotype frequency distributions in these three groups in both cases and controls. No significant difference was found for any of the comparisons (data not shown).

\section{Discussion}

The present study confirmed the well-established association between the APOE gene and AD. All three APOE alleles $(\varepsilon 2, \varepsilon 3$ and $\varepsilon 4)$ showed dose effects on the risk for AD, and followed a co-dominant mode of inheritance. We also examined, for the first time to our knowledge for a trait in neuropsychiatry, a mathematical measure of the predictive value of each $A P O E$ allele and genotype for $A D$ diagnosis risk.

In addition to a significant association between the APOE gene and Alzheimer's disease, subgroup analyses revealed an association with subtypes based on age of onset, family history, and sex. The $\varepsilon 4$ allele, the $\varepsilon 4 / \varepsilon 4$ genotype and the $\varepsilon 3 / \varepsilon 4$ genotype were risk factors for $\mathrm{AD}$; the $\varepsilon 2$ allele, the $\varepsilon 3$ allele, the $\varepsilon 2 / \varepsilon 3$ genotype and the $\varepsilon 3 / \varepsilon 3$ genotype were protective factors for AD. These findings are consistent with those in most previous studies [e.g., [14,15]]. Further comparisons among AD subgroups and controls showed 
Table 4: Distributions of the frequencies of the genotypes with ascending APOE allele number

\begin{tabular}{|c|c|c|c|c|c|c|c|c|c|c|c|c|c|c|c|c|c|c|c|c|c|c|c|c|}
\hline & \multicolumn{6}{|c|}{ Number of $\varepsilon 2$ alleles } & \multicolumn{2}{|c|}{ Chi-Square test for trend } & \multicolumn{6}{|c|}{ Number of $\varepsilon 3$ alleles } & \multicolumn{2}{|c|}{ Chi-Square test for trend } & \multicolumn{6}{|c|}{ Number of $\varepsilon 4$ alleles } & \multicolumn{2}{|c|}{ Chi-Square test for trend } \\
\hline & \multicolumn{2}{|c|}{0} & \multicolumn{2}{|l|}{ I } & \multicolumn{2}{|c|}{2} & \multirow[t]{2}{*}{$\chi^{2}$} & \multirow[t]{2}{*}{$P$} & \multicolumn{2}{|l|}{0} & \multicolumn{2}{|l|}{1} & \multicolumn{2}{|c|}{2} & \multirow[t]{2}{*}{$\chi^{2}$} & \multirow[t]{2}{*}{$P$} & \multicolumn{2}{|l|}{0} & \multicolumn{2}{|c|}{1} & \multicolumn{2}{|l|}{2} & \multirow[t]{2}{*}{$\chi^{2}$} & \multirow[t]{2}{*}{$\mathrm{P}$} \\
\hline & $f$ & $N$ & $f$ & $N$ & $f$ & $N$ & & & $f$ & $N$ & $f$ & $\mathrm{~N}$ & $f$ & $\mathrm{~N}$ & & & $f$ & $\mathrm{~N}$ & $f$ & $\mathrm{~N}$ & $f$ & $N$ & & \\
\hline AD & 0.953 & 342 & 0.047 & 17 & 0 & 0 & 11.32 & 0.001 & 0.150 & 54 & 0.465 & 167 & 0.384 & 138 & 43.02 & $<0.0001$ & 0.421 & $15 \mid$ & 0.440 & 158 & 0.139 & 50 & & $<0.0001$ \\
\hline EOAD & 0.965 & 166 & 0.035 & 6 & 0 & 0 & 9.73 & 0.002 & 0.209 & 36 & 0.401 & 69 & 0.390 & 67 & 37.41 & $<0.0001$ & 0.419 & 72 & 0.378 & 65 & 0.203 & 35 & 56.72 & $<0.0001$ \\
\hline LOAD & 0.946 & 174 & 0.054 & 10 & 0 & 0 & 5.69 & 0.017 & 0.098 & 18 & 0.516 & 95 & 0.386 & 71 & 26.27 & $<0.0001$ & 0.424 & 78 & 0.494 & 91 & 0.082 & 15 & 42.63 & $<0.0001$ \\
\hline $\mathrm{FH}^{+}$ & 0.971 & 168 & 0.029 & 5 & 0 & 0 & 11.46 & 0.001 & 0.162 & 28 & 0.497 & 86 & $0.34 I$ & 59 & 41.06 & $<0.0001$ & 0.370 & 64 & 0.468 & 81 & 0.162 & 28 & 61.13 & $<0.0001$ \\
\hline $\mathrm{FH}^{-}$ & 0.939 & 170 & 0.061 & 11 & 0 & 0 & 4.49 & 0.034 & 0.144 & 26 & 0.431 & 78 & 0.425 & 77 & 24.67 & $<0.0001$ & 0.464 & 84 & 0.414 & 75 & 0.122 & 22 & 38.60 & $<0.0001$ \\
\hline Male & 0.936 & 132 & 0.064 & 9 & 0 & 0 & 3.29 & 0.069 & 0.121 & 17 & 0.489 & 69 & 0.390 & 55 & 16.00 & $<0.0001$ & 0.433 & 61 & 0.468 & 66 & 0.099 & 14 & 24.98 & $<0.0001$ \\
\hline Female & 0.963 & 210 & 0.037 & 8 & 0 & 0 & 8.02 & 0.005 & 0.170 & 37 & 0.450 & 98 & 0.381 & 83 & 26.33 & $<0.0001$ & 0.413 & 90 & 0.422 & 92 & 0.165 & 36 & 38.04 & $<0.0001$ \\
\hline Controls & 0.878 & 216 & 0.122 & 30 & 0 & 0 & & & 0.053 & 13 & 0.293 & 72 & 0.654 & 161 & & & 0.760 & 187 & 0.203 & 50 & 0.037 & 9 & & \\
\hline Male & 0.870 & 100 & 0.130 & 15 & 0 & 0 & & & 0.061 & 7 & 0.278 & 32 & 0.661 & 76 & & & 0.774 & 89 & 0.183 & 21 & 0.043 & 5 & & \\
\hline Female & 0.885 & 116 & 0.115 & 15 & 0 & 0 & & & 0.046 & 6 & 0.305 & 40 & 0.649 & 85 & & & 0.748 & 98 & 0.221 & 29 & 0.031 & 4 & & \\
\hline
\end{tabular}

f, N, AD, EOAD, LOAD, Controls, and the comparing methods see Tables I and 2.

$\alpha$ was set at 0.017 (or 0.003 ) for each Chi-Square test for trend analysis in overall AD (or AD subgroups), referring to Tables I and 2. 


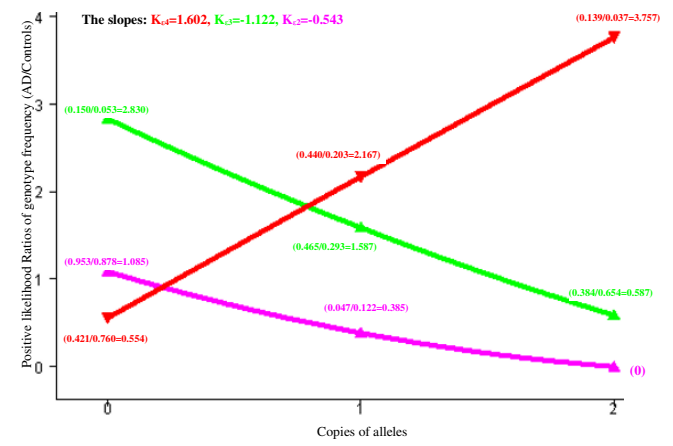

Figure 2

Dose effects of APOE gene alleles. $\mathrm{X}$-axis represents the copies of alleles ( $\varepsilon 2$ allele, pink line; $\varepsilon 3$ allele, green line; $\varepsilon 4$ allele, red line); $Y$-axis represents the positive likelihood ratios of genotype frequency (in AD cases vs. in Controls)

that the $\varepsilon 4 / \varepsilon 4$ genotype frequency was significantly higher in EOAD than in LOAD and controls, suggesting that the $\varepsilon 4 / \varepsilon 4$ genotype can significantly reduce the age-of-onset. This is consistent with findings in other studies [e.g., [19]].

We also found that the PPV of the $\varepsilon 4 / \varepsilon 4$ genotype was significantly higher in females $(48.4 \%)$ than in males (28.9\%). Although the $\varepsilon 4 / \varepsilon 4$ genotype frequency in female $\mathrm{AD}$ cases was significantly higher than in female controls, we found no significant difference in males. These results suggest that the $\varepsilon 4 / \varepsilon 4$ genotype is a stronger risk factor for females than for males. This is consistent with findings from other studies [e.g., [41-43]]. However since sex distributions were not well matched between cases and controls, it could also reflect a stratification effect by sex.

Both the chi-square test for trend and the regression analyses revealed that the risk for $\mathrm{AD}$ increased significantly with the number of $\varepsilon 4$ alleles. This is also consistent with findings from other studies [e.g., [18]]. In addition, we found that the risk for AD decreased with the number of $\varepsilon 2$ or $\varepsilon 3$ alleles. Furthermore, the dose of $A P O E$ alleles was linearly related to $\mathrm{LR}^{+}$. These results are all compatible with those from our allelewise analyses.

This information is of importance in predicting the development of AD in early life. However, not all subjects with the $\varepsilon 4$ allele develop $\mathrm{AD}$, nor do all $\mathrm{AD}$ patients carry the $\varepsilon 4$ allele. On the other hand, not all subjects are protected against $\mathrm{AD}$ by the $\varepsilon 2$ and $\varepsilon 3$ alleles. Therefore, it is important to estimate the probability that these allele carriers will develop $\mathrm{AD}$. We found that the $\varepsilon 4 / \varepsilon 4$ genotype had a PPV of $39.90 \%$ and an $\mathrm{LR}^{+}$of 3.76 for AD. In other words, a subject carrying two $\varepsilon 4$ alleles has a probability of $39.90 \%$ to develop AD. In contrast, a subject carrying one $\varepsilon 4$ allele and one $\varepsilon 3$ allele has a probability of $28.80 \%$ to develop $\mathrm{AD}$, and a subject carrying one $\varepsilon 4$ allele and one $\varepsilon 2$ allele has a probability of $10.82 \%$ to develop AD. Based on the interpretation of $\mathrm{LRs}^{+}$by Ebell [39], the presence of $A P O E$ alleles can only mildly change the risk for $\mathrm{AD}$, despite a highly significant association with $\mathrm{AD}$. This implies that $A P O E$ genotype testing can provide evidence on whether a subject may develop AD, but it is not sufficient as an independent screening or predictive test for the diagnosis of AD [44]. Additionally, we found the following order for both PPVs and $\mathrm{LRs}^{+}$of APOE alleles and genotypes with respect to the diagnosis of AD: $\varepsilon 4 / \varepsilon 4>\varepsilon 4>$ $\varepsilon 3 / \varepsilon 4>\varepsilon 3>\varepsilon 2 / \varepsilon 4>\varepsilon 3 / \varepsilon 3>\varepsilon 2>\varepsilon 2 / \varepsilon 3$ (see Table 3 ). This order shows that: (1) $\varepsilon 4 / \varepsilon 4>\varepsilon 4$, suggesting that the risk for $\mathrm{AD}$ increases with the number of $\varepsilon 4$ alleles; (2) $\varepsilon 4>\varepsilon 3 /$ $\varepsilon 4$ and $\varepsilon 3 / \varepsilon 4>\mathrm{AD}$ population prevalence, suggesting that the $\varepsilon 3$ allele reduces the risk for $\mathrm{AD}$ conveyed by the $\varepsilon 4$ allele, but the protective effect of $\varepsilon 3$ is weaker than the risk effect of $\varepsilon 4$; (3) $\varepsilon 3 / \varepsilon 3<\varepsilon 3$, suggesting that the protection against $\mathrm{AD}$ increases with the number of $\varepsilon 3$ alleles; (4) $\varepsilon 3$ $>\varepsilon 2 / \varepsilon 3$ and $\varepsilon 2>\varepsilon 2 / \varepsilon 3$, suggesting that the protective effect on $\mathrm{AD}$ risk for a genotype containing two protective alleles is greater than that for a genotype containing only one of the protective alleles; (5) $\varepsilon 3>\varepsilon 2$ and $\varepsilon 3 / \varepsilon 3>\varepsilon 2 / \varepsilon 3$, suggesting that the $\varepsilon 2$ allele is a stronger protective factor for $\mathrm{AD}$ than the $\varepsilon 3$ allele, which is reflected in their positions on the $\mathrm{Y}$ axis in the figure depicting the dose effect (Figure 2); and (6) $\varepsilon 3 / \varepsilon 4>\mathrm{AD}$ population prevalence, but $\varepsilon 2 / \varepsilon 3<\varepsilon 3 / \varepsilon 3<\varepsilon 3<\mathrm{AD}$ population prevalence, suggesting that without $\varepsilon 4$, the $\varepsilon 3$ allele and any genotypes containing the $\varepsilon 3$ allele cannot increase risk for $\mathrm{AD}$, that is, it is $\varepsilon 4$, not $\varepsilon 3$, that contributes to the increased risk of AD associated with the $\varepsilon 3 / \varepsilon 4$ genotype. Similarly, the PPV for $\varepsilon 2 / \varepsilon 4$ $<\mathrm{AD}$ population prevalence (i.e., a protective effect), but $\varepsilon 4 / \varepsilon 4>\varepsilon 4>\varepsilon 3 / \varepsilon 4>\mathrm{AD}$ population prevalence (i.e., a risk effect), suggesting that without $\varepsilon 2$, the $\varepsilon 4$ allele and any genotypes containing the $\varepsilon 4$ allele (e.g., $\varepsilon 4 / \varepsilon 4$ and $\varepsilon 3 / \varepsilon 4$ ) do not have a protective effect; it is $\varepsilon 2$, not $\varepsilon 4$, that results in the $\varepsilon 2 / \varepsilon 4$ genotype having a lower PPV. Taken together, the order of these effects suggests that $\varepsilon 4$ is a doseresponse risk factor for developing $\mathrm{AD}, \varepsilon 2$ is a doseresponse protective factor, and $\varepsilon 3$ is a relatively weaker dose-response protective factor. These findings are consistent with the results of our allelewise analyses, chisquare tests for trends, and logistic regression analyses.

There has been debate about whether the presence of a "bad" allele (i.e., $\varepsilon 4$ ) or of a "good" allele ( $\varepsilon 2$ or $\varepsilon 3$ ), or both, contribute to the association between $A P O E$ and $\mathrm{AD}$. The answer to this question is important for the development of specific therapies for $\mathrm{AD}$ [45]. Our results 
tend to show that both the "bad" allele $(\varepsilon 4)$ and the "good" alleles ( $\varepsilon 2$ and $\varepsilon 3$ ) are involved in the risk for AD, consistent with codominant inheritance. These findings are supported by the evidence from studies on the neuropathological processes involved in $\mathrm{AD}$ [e.g., [6]].

Noting both the close interaction between the APOE and the tau proteins and the physical proximity of the Tau and STH genes, we investigated the correlation between effects of the APOE and STH gene polymorphisms. We found no significant interactive effect between these two genes either in cases or in controls. This finding was consistent with our regression analysis and the studies by Conrad et al. [23] and Peplonska et al. [22]. Thus, the APOE gene affects risk for AD through a pathway independent of the STH gene polymorphism we queried.

We also found no associations between STH alleles and $\mathrm{AD}$, even after adjusting for potential confounders, including age, sex, and family history. Neither the genotype analysis nor the gene-dose analysis showed any association. Our results suggest that STH may not be a risk gene for AD. The initial positive findings by Conrad et al. [23] may be attributable to sampling bias in the context of small sample sizes (51 AD cases; 30 healthy controls). Our sample size (286 AD cases; 197 healthy controls) is much larger than theirs. Moreover, our negative findings are in good agreement with many other studies, which also have much larger sample sizes (e.g., 499 AD cases and 402 controls by Verpillat et al. [25]; 225 AD cases and 144 controls by Streffer et al. [27]; 200 AD cases and 458 controls by Clark et al. [28]; 690 AD families, 903 AD cases and 320 controls by Oliveira et al. [29]; 100 AD cases and 100 controls by Peplonska et al. [22]). Additionally, the Q allele frequency $(0.867)$ in controls in the initial study is similar to both controls and cases in our and the other negative studies; but the $\mathrm{Q}$ allele frequency (0.676) in $\mathrm{AD}$ cases is significantly lower than those in cases and controls in most of the published studies [22,25,27-29]. So far, there has been only one study [24] reporting a replicated positive finding between the genotype STH RR and $\mathrm{AD}(\mathrm{p}=0.04)$, but even this positive finding is only nominal and does not survive after Bonferroni correction. Therefore, we conclude that the STH gene Q7R variation does not play an important role in the pathology of $\mathrm{AD}$.

\section{Competing interests}

The author(s) declare that they have no competing interests.

\section{Authors' contributions}

LZ designed the study, genotyped most of the subjects, analyzed and interpreted the data, and drafted the manuscript. CHVD collected the samples, participated in the design of the study, interpreted the data, and critically revised the manuscript. XL participated in designing the study, genotyping some subjects, analyzing and interpreting the data, and drafting the manuscript. HRK collected the samples, contributed to the interpretation, and made critical comments on the manuscript. BZY contributed to statistical analysis and data interpretation. JG obtained the funding, prepared the samples, supervised the study, interpreted the data, and made critical comments on the manuscript. All authors read and approved the final manuscript.

\section{Acknowledgements}

This work was supported in part by funds from the U.S. Department of Veterans Affairs (the VA Medical Research Program, and the VA Connecticut-Massachusetts Mental Illness Research, Education and Clinical Center [MIRECC], and the VA Research Enhancement Award Program [REAP] research center), National Institute of Mental Health (NIMH) grant K02-MHO I387, National Institute on Drug Abuse (NIDA) grants ROI-DA I 2849, ROI-DA I 2690, and K24-DA I 5 I05, National Institute on Alcohol Abuse and Alcoholism (NIAAA) grants ROIAA0I60I5-0I, ROI-AAI I330, K08-AAI3732 and K24-AA I3736, National Center for Research Resources (NCRR) grant MOI-RR06192 (University of Connecticut General Clinical Research Center), and Alcoholic Beverage Medical Research Foundation (ABMRF) grant award R06932 (X Luo). Ann Marie Lacobelle provided excellent technical assistance.

\section{References}

I. Masters C, Simms G, Weinman N, Multhaup G, McDonald B, Beyreuther K: Amyloid plaque core protein in Alzheimer's disease and Down's syndrome. Proc Natl Acad Sci USA 1985, 82:4245-4249.

2. Sennvik K: A study of $\beta$-secretase cleaved Alzheimer amyloid precursor protein. In Novum, Huddinge Sweden: Karolinska University Press; 2002:9.

3. Mahley RW, Huang Y, Rall SC: Pathogenesis of type III hyperlipoproteinemia (dysbetalipoproteinemia). Questions, quandaries, and paradoxes. J Lipid Res 1999, 40:1933-1949.

4. Puglielli L, Tanzi RE, Kovacs DM: Alzheimer's disease: the cholesterol connection. Nat Neurosci 2003, 6:345-35I.

5. Namba Y, Tomonaga M, Kawasaki H, Otomo E, Ikeda K: Apolipoprotein $E$ immunoreactivity in cerebral amyloid deposits and neurofibrillary tangles in Alzheimer's disease and kuru plaque amyloid in Creutzfeldt-Jakob disease. Brain Res 1991, 541:163-166.

6. Munson GW, Roher AE, Kuo YM, Gilligan SM, Reardon CA, Getz GS, LaDu MJ: SDS-Stable Complex Formation between Native Apolipoprotein E3 and $\beta$-Amyloid Peptides. Biochemistry 2000, 39:16119-16124.

7. Kosik K, Joachim C, Selkoe DJ: Microtubule-associated protein tau $(\tau)$ is a major antigenic component of paired helical filaments in Alzheimer's disease. Proc Natl Acad Sci 1986, 83:4044-4048.

8. Farrer M, Skipper L, Berg M, Bisceglio G, Hanson M, Hardy J, Adam A, Gwinn-Hardy K, Aasly J: The tau HI haplotype is associated and the risk of Alzheimer disease among African Americans, Whites, and Hispanics. J Am Med Assoc 1998, 279:75 I-755.

9. Lilius L, Froelich Fabre S, Basun H, Forsell C, Axelman K, Mattila K, Andreadis A, Viitanen M, Winblad B, Fratiglioni L, Lannfelt L: Tau gene polymorphisms and apolipoprotein $E$ epsilon 4 may interact to increase risk for Alzheimer's disease. Neurosci Lett 1999, 277:29-32.

10. Bullido MJ, Aldudo J, Frank A, Coria F, Avila J, Valdivieso F: A polymorphism in the tau gene associated with risk for Alzheimer's disease. Neurosci Lett 2000, 278:49-52.

II. Russ C, Powell JF, Zhao J, Baker M, Hutton M, Crawford F, Mullan M, Roks G, Cruts M, Lovestone S: The microtubule associated protein Tau gene and Alzheimer's disease-an association study and meta-analysis. Neurosci Lett 2001, 3 14:92-96. 
12. De Silva R, Hardy J, Crook J, Khan N, Graham EA, Morris CM, Wood NW, Lees AJ: The tau locus is not significantly associated with pathologically confirmed sporadic Parkinson's disease. Neurosci Lett 2002, 330:20I-203.

13. Zannis VI, Breslow JL, Utermann G, Mahley RW, Weisgraber KH, Havel RJ, Goldstein JL, Brown MS, Schonfeld G, Hazzard WR, Blum $\mathrm{C}$ : Proposed nomenclature of apoE isoproteins, apoE genotypes, and phenotypes. Lipid Res 1982, 23:911-914.

14. Oyama F, Shimada H, Oyama R, Ihara Y: Apolipoprotein E genotype, Alzheimer's pathologies and related gene expression in the aged population. Brain Res Mol Brain Res 1995, 29:92-98.

15. Korovaitseva Gl, Shcherbatykh TV, Selezneva NV, Gavrilova SI, Golimbet VE, Voskresenskaia NI, Rogachev El: Genetic association between the apolipoprotein $E$ (ApoE) gene alleles and various forms of Alzheimer's disease. Genetika 200I, 37:529-535.

16. Combarros O, Garcia-Roman M, Fontalba A, Fernandez-Luna JL, Llorca J, Infante J, Berciano J: Interaction of the H63D mutation in the hemochromatosis gene with the apolipoprotein $E$ epsilon 4 allele modulates age at onset of Alzheimer's disease. Dement Geriatr Cogn Disord 2003, I 5: I5I-I54.

17. Marui W, Iseki E, Sugiyama N, Matsumura T, Suzuki K, Odawara T, Hino $\mathrm{H}$, Kosaka K: A Japanese family with familial Alzheimer's disease associated with presenilin I mutation: relationship between younger age of onset and ApoE gene polymorphism. No To Shinkei 2003, 55:349-353.

18. Corder EH, Saunders AM, Strittmatter WJ, Schmechel DE, Gaskell PC, Small GW, Roses AD, Haines JL, Pericak-Vance MA: Gene dose of apolipoprotein E type 4 allele and the risk of Alzheimer's disease in late onset families. Science 1993, 261:921-923.

19. Goldstein FC, Ashley AV, Gearing M, Hanfelt J, Penix L, Freedman LJ, Levey Al: Apolipoprotein E and age at onset of Alzheimer's disease in African American patients. Neurology 2001, 57:1923-1925.

20. Mori E, Lee K, Yasuda M, Hashimoto M, Kazui H, Hirono N, Matsui M: Accelerated hippocampal atrophy in Alzheimer's disease with apolipoprotein E epsilon4 allele. Ann Neurol 2002, 5 I:209-2|4.

21. De Silva R, Hope A, Pittman A, Weale ME, Morris HR, Wood NW, Lees AJ: Strong association of the Saitohin gene Q7 variant with progressive supranuclear palsy. Neurology 2003, 61:407-409.

22. Peplonska B, Zekanowski C, Religa D, Czyzewski K, Styczynska M, Pfeffer A, Gabryelewicz T, Golebiowski M, Luczywek E, Wasiak B, Barczak A, Chodakowska M, Barcikowska M, Kuznicki J: Strong association between Saitohin gene polymorphism and tau haplotype in the Polish population. Neurosci Lett 2003, 348:163-166.

23. Conrad C, Vianna C, Freeman M, Davies P: A polymorphic gene nested within an intron of the tau gene: implications for Alzheimer's disease. Proc Natl Acad Sci USA 2002, 99:775I-7756.

24. Combarros O, Rodero L, Infante J, Palacio E, Llorca J, Fernandez-Viadero C, Pena N, Berciano J: Age-dependent association between the Q7R polymorphism in the Saitohin gene and sporadic Alzheimer's disease. Dement Geriatr Cogn Disord 2003, 16:132-135.

25. Verpillat $P$, Camuzat $A$, Hannequin D, Thomas-Anterion $C$, Puel $M$, Belliard S, Dubois B, Didic M, Michel BF, Lacomblez L, Moreaud O Sellal F, Golfier V, Campion D, Clerget-Darpoux F, Brice A: Association between the extended tau haplotype and frontotemporal dementia. Arch Neurol 2002, 59:935-939.

26. Zekanowski C, Peplonska B, Styczynska M, Gustaw K, Kuznicki J, Barcikowska M: Mutation screening of the MAPT and STH genes in Polish patients with clinically diagnosed frontotemporal dementia. Dement Geriatr Cogn Disord 2003, 16:|26-|3|.

27. Streffer JR, Papassotiropoulos A, Kurosinski P, Signorell A, Wollmer MA, Tsolaki M, lakovidou V, Hörndli F, Bosset J, Götz J, Nitsch RM, Hock C: Saitohin gene is not associated with Alzheimer's disease. J Neurol Neurosurg Psychiatry 2003, 74:362-363.

28. Clark LN, Levy G, Tang MX, Mejia-Santana H, Ciappa A, Tycko B, Cote LJ, Louis ED, Mayeux R, Marder K: The Saitohin 'Q7R' polymorphism and tau haplotype in multi-ethnic Alzheimer disease and Parkinson's disease cohorts. Neurosci Lett 2003, 347:17-20.

29. Oliveira SA, Martin ER, Scott WK, Nicodemus KK, Small GW, Schmechel DE, Doraiswamy PM, Roses AD, Saunders AM, Gilbert JR, Haines JL, Vance JM, Pericak-Vance MA: The Q7R Saitohin gene polymorphism is not associated with Alzheimer disease. Neurosci Lett 2003, 347: |43-146.

30. McKhann G, Drachmann D, Folstein M, Katzman R, Price D, Stadlan EM: Clinical diagnosis of Alzheimer's disease: report of the NINCDS-ADRDA Work Group under the auspices of Department of Health and Human Services task force on Alzheimer's disease. Neurology 1989, 34:939-944.

3I. Breitner JCS, Folstein MF: Familial Alzheimer's disease: a prevalent disorder with specific clinical features. Psychol Med 1984 , I 4:63-80.

32. Silverman JM, Breitner JCS, Mohs RC, Davis KL: Reliability of the family history method in genetic studies of Alzheimer's disease and related dementias. Am J Psychiatry 1986, I 43:1279-1282

33. Spitzer RL, Endicott J: Schedule for Affective Disorders and Schizophrenia: Lifetime version. In New York: New York Biometrics Research Division New York State Psychiatric Institute; 1975.

34. Folstein MF, Folstein SE, McHugh PR: "Mini-mental state". A practical method for grading the cognitive state of patients for the clinician. I Psychiatr Res 1975, I 2: | 89-198.

35. Tsai MS, Tangalos EG, Petersen RC, Smith GE, Schaid DJ, Kokmen E, Ivnik RJ, Thibodeau SN: Apolipoprotein E: risk factor for Alzheimer disease. Am J Hum Genet 1994, 54:643-649.

36. Holm S: A Simple sequentially rejective multiple test procedure. Scand J Stat 1979, 6:65-70.

37. Rosner B: Fundamentals of Biostatistics. 5th edition. Australia: Duxbury; 1979.

38. Pfeffer RI, Afifi AA, Chance JM: Prevalence of Alzheimer's disease in a retirement community. Am 」 Epidemiol 1987, I 25:420-436.

39. Ebell MH: Evidence-Based Diagnosis: a handbook of clinical prediction rules. New York: Springer; 2001:6-8.

40. Gustafson TL: True Epistat Version 6.0. Richardson, TX: Epistat Services 1992

4I. Palumbo B, Parnetti L, Nocentini G, Cardinali L, Brancorsini S, Riccardi C, Senin U: Apolipoprotein-E genotype in normal aging, age-associated memory impairment, Alzheimer's disease and vascular dementia patients. Neurosci Lett 1997, 23 1:59-61.

42. Bretsky PM, Buckwalter JG, Seeman TE, Miller CA, Poirier J, Schellenberg GD, Finch CE, Henderson VW: Evidence for an interaction between apolipoprotein E genotype, gender, and Alzheimer disease. Alzheimer Dis Assoc Disord 1999, 13:216-221.

43. De-Andrade FM, Larrandaburu M, Callegari-Jacques SM, Gastaldo G, Hutz MH: Association of apolipoprotein E polymorphism with plasma lipids and Alzheimer's disease in a Southern Brazilian population. Braz J Med Biol Res 2000, 33:529-537.

44. Panza F, Introno AD, Colacicca AM, Basile AM, Capurso C, Kehoe PG, Capurso A, Solfrizzi V: Vascular risk and genetics of Sporadic Late-Onset Alzheimer's Disease. J Neural Transm 2004, I I I:69-89.

45. Ashford JW: ApoE: Is it the absence of good or the presence of bad? J Alzheimer Dis 2002, 4:14I-143.

Publish with Bio Med Central and every scientist can read your work free of charge

"BioMed Central will be the most significant development for disseminating the results of biomedical research in our lifetime. "

Sir Paul Nurse, Cancer Research UK

Your research papers will be:

- available free of charge to the entire biomedical community

- peer reviewed and published immediately upon acceptance

- cited in PubMed and archived on PubMed Central

- yours - you keep the copyright
BioMedcentral 